\title{
RANCANGAN BANGUN SISTEM KONTROL OTOMATIS PENGATUR SUHU DAN KELEMBAPAN KANDANG AYAM BROILER MENGGUNANAKAN ARDUINO
}

\author{
Muh Fuad Mansyur \\ Prodi Informatika, Fakultas Teknik, Universitas Sulawesi Barat \\ Muh.fuadm@unsulbar.ac.id
}

\begin{abstract}
ABSTRAK
Para peternak ayam pedaging masih menggunakan cara manual dalam menjaga suhu optimal kandang. Rutinitas tersebut menyebabkan suatu masalah yaitu kelupaan peternak dalam menjaga suhu dan kelembaban pada kandang ternaknya. Maka di Buatlah Sistem otomatisasi kandang ternak ini menggunakan Arduino sebagai pengontrol keseluruhan sistem. Alat yang di gunakan pada sistem ini yaitu arduino Mega 2560, Sensor DHT11, Fan DC, Icd 16x2, Motor Driver L293D, Driver Motor DC to AC 220V, Lampu Pijar, fan, Ethernet Shield W5100,TP Link dan Modem GSM. Dengan metode literatur dan eksperimental yang memanipulasi atau mengontrol situasi alamiah dengan cara membuat kondisi buatan (artificial condition). Pembuatan kondisi ini dilakukan oleh si peneliti. Dengan demikian, penelitian eksperimen adalah penelitian yang dilakukan dengan mengadakan menipulasi terhadap objek penelitian, serta adanya kontrol yang disengaja terhadap objek penelitian tersebut. Sistem pemanas berjalan berdasarkan 1 inputan dari DHT11 yang berfungsi membaca suhu dan kelembaban pada kandang. PWM digunakan sebagai penentu tingkat intensitas cahaya dan kecepatan putaran kipas pada kandang. Hasil dari model system Kontrol Otomatis ini adalah mampu mempertahankan keseimbangan pada kondisi Suhu $31^{\circ}-34^{\circ} \mathrm{C}$ dan Kelembaban $50-60 \%$, suhu tersebut sudah sesuai oleh standar suhu yang di butuhkan oleh ayam broiler pada masa Starter.

Kata Kunci : : Arduino, DHT11, Ayam Broiler, Pulse Width Modulation, Sistem Kontrol
\end{abstract}

\section{ABSTRACT}

The broiler breeders still use the manual way in maintaining the optimal temperature of the cage. The routine causes a problem that is forgetting the breeder in maintaining the temperature and humidity in the cattle pen. So in Make this cage livestock automation system using Arduino as a system-wide controller. The tools used in this system are arduino Mega 2560, DHT11 Sensor, DC Fan, 16x2 Icd, L293D Motor Driver, DC to AC 220V Motor Driver, Incandescent Lamp, Ethernet Shield W5100, TP Link and GSM Modem. With literature and experimental methods that manipulate or control the natural situation by creating artificial conditions (artificial condition). Making this condition done by the researcher. Thus, experimental research is research conducted by manipulating the object of research, as well as the existence of deliberate control of the object of the study. Heating system runs based on 1 input from DHT11 which serves to read the temperature and humidity in the cage. PWM is used as a determinant of light intensity level and fan speed at the cage. The result of this Automatic Control system model is able to maintain the balance in conditions of Temperature $31^{\circ}-34^{\circ} \mathrm{C}$ and $50-60 \%$ Humidity, the temperature is in accordance with the standard temperature required by broiler chickens in the Starter. Keywords: Arduino, DHT11, Broiler Chicken, Pulse Width Modulation.control system. 


\section{Pendahuluan}

Indonesia sebagai negara yang memiliki bidang peternakan yang sangat besar, hampir setiap penduduk Indonesia adalah sebagai peternak ayam, sapi, kampung dan terutama ayam broiler. Usaha ternak ayam broiler sejak tahun 1980 sampai 2017 semakin menonjol peranya dalam kesenjangan terhadap meningkatnya kebutuhan akan daging. Daging ayam broiler dipilih sebagai salah satu alternatif, karena kita tahu bahwa prospek ayam broiler sangat efesien di produksi. Dalam jangka 6-8 minggu ayam tersebut sanggup mencapai berat hidup $1,5 \mathrm{~kg}-2 \mathrm{~kg}$,dan secara umum dapat memenuhi selera konsumen masyarakat .

Prospek ternak ayam broiler cukup dinilai baik akan permintaan pasar selalu meningkat, sejalan dengan kesadaran masyarakat akan perubahan gizi hewani. Produksi ayam broiler saat ini berkembang sangat pesat dan peluang pasar yang menguntungkan dapat meningkatkan nilai ekonomi .Dagingnya di dalam pesta keagamaan netral, lain halnya dengan daging sapi bagi umat Hindu, dan daging babi bagi umat Islam, di tinjau dari segi ekonomisnya, khususnya ayam ras potong atau ayam negri yang sudah populer dengan sebutan broiler, merupakan ayam yang bisa diusahakan secara efisien, sebab broiler merupakan ternak potong yang paling cepat bisa dipotong di banding dengan ternak yang lainnya.

Peternakan ayam skala besar rata-rata memiliki luas dari 1 hektar hingga 5 hektar. Dengan kandang seluas itu tentunya tidak mudah untuk pegawai dan pemilik peternakan melakukan pengawasan berkala secara cepat terhadap kondisi kandang. padahal suhu dan kelembaban pada kandang memerlukan pengawasan secara cepat dikarenakan dua parameter ini mudah sekali mengalami perubahan dan memiliki nilai yang mungkin berbeda-beda pada setiap kandang. Broiler adalah istilah yang biasa dipakai untuk menyebut ayam hasil budidaya teknologi peternakan yang memiliki karakteristik ekonomi dengan ciri khas pertumbuhan yang cepat, sebagai penghasil daging dengan

Konversi pakan rendah dan siap dipotong pada usia yang relatif muda. Ayam broiler merupakan hasil persilangan antara bangsa ayam cornish dari inggris dengan ayam white play mounth rock dari Amerika. Ayam Broiler bisa mengatur suhu tubuhnya namun tidak dapat optimal ketika kandang terjadi perubahan suhu dan kelembaban drastis, oleh 
karena itu peran pemanas (lampu) sangat penting untuk menjaga suhu kandang tetap dalam zona nyaman ayam. Suhu yang dibutuhkan ayam tipe broiler pada kandang adalah $30^{\circ} \mathrm{C}-34^{\circ} \mathrm{C}$ dan kelembabannya adalah $50 \%-60 \%$. Untuk menangani kondisi tersebut dibutuhkan suatu sistem yang dapat dioperasikan menggunakan Arduino dan pendeteksi suhu dan kelembaban pada peternakan ayam. Dari permasalahan di atas, muncul suatu pemikiran untuk membuat sebuah kandang khusus untuk Broiler yang dapat mengendalikan suhu dan kelembaban secara otomatis. Alat ini menggunakan sensor DHT11 yang berfungsi sebagai pendeteksi suhu dan kelembaban yang ada di dalam kandang ayam tersebut. Sensor DHT11 memiliki sinyal transmisi jarak hingga 20 meter.

\section{Kajian Literatur}

\subsection{Sistem Pengendalian}

Sistem pengendalian berfungsi untuk mengendalikan jalannya proses agar variabel proses yang sedang diukur dapat dikendalikan dan diatur sesuai dengan nilai yang dikehendaki (setpoint). Sistem pengendalian mempunyai beberapa persyaratan umum, antara lain:

1. Setiap sistem pengendalian harus stabil.

2. Sistem pengendalian harus mempunyai kestabilan relatif yang layak.

3. Kecepatan respon harus cukup cepat dan menunjukkan peredaman yang layak.

4. Suatu sistem pengendalian juga harus mampu memperkecil kesalahan sampai nol atau sampai pada suatu harga yang dapat ditoleransi.

\subsection{Arduino}

Arduino merupakan perangkat keras sekaligus perangkat lunak yang memungkinkan siapa saja melakukan pembuatan prototype suatu rangkaian elektronika yang berbasis mikrokontroller dengan mudah dan cepat. Papan Arduino bekerja dengan tegangan masukan 7-12V. Adapun tegangan kerja yang digunakan adalah 5V. Papan ini mengandung 14 pin digital dan 6 di antara pin-pin tersebut dapat bertindak sebagai pin-pin PWM (Pulse Width Modulation), yang memungkinkan untuk mendapatkan isyarat analaog di pin digital., PWM berguna misalnya untuk meredupkan LED atau mengatur kecepatan putar motor. 


\section{Journal Of Computer and Information System (J-CIS)}

ISSN 2622-0881 (online)

\subsection{PWM (Pulse-Width Modulation)}

PWM adalah singkatan dari Pulse Width Modulation. Pada Arduino, sinyal PWM adalah sinyal yang beroperasi pada frekuensi $500 \mathrm{~Hz}$ (ini akan kita bahas pada paragraf selanjutnya). Pada board arduino Uno, pin yang bisa dimanfaatkan untuk PWM adalah pin yang diberi tanda tilde $(\sim)$, yaitu pin 3, 5, 6, 9, 10, dan pin 11. pin tersebut merupakan pin yang bisa difungsikan untuk input analog atau output analog.

PWM pada arduino bekerja pada frekuensi $500 \mathrm{~Hz}$, artinya 500 siklus/ketukan dalam satu detik. Untuk setiap siklus, kita bisa memberi nilai dari 0 hingga 255 . Ketika kita memberikan angka 0 , berarti pada pin tersebut tidak akan pernah bernilai 5 volt (pin selalu bernilai 0 volt). Sedangkan jika kita memberikan nilai 255, maka sepanjang siklus akan bernilai 5 volt (tidak pernah 0 volt). Jika kita memberikan nilai 127 (kita anggap setengah dari 0 hingga 255, atau $50 \%$ dari 255), maka setengah siklus akan bernilai 5 volt, dan setengah siklus lagi akan bernilai 0 volt. Sedangkan jika jika memberikan 25\% dari 255 (1/4 * 255 atau 64), maka $1 / 4$ siklus akan bernilai 5 volt, dan $3 / 4$ sisanya akan bernilai 0 volt, dan ini akan terjadi 500 kali dalam 1 detik.

\subsection{Sensor}

Pada sistem elektronis, sensor dipandang sebagai sebuah perangkat atau device yang berfungsi untuk mengubah suatu besaran fisik menjadi besaran listrik, sehingga keluarannya dapat diolah dengan rangkaian listrik atau sistem digital. Terkait dengan perkembangan teknologi yang begitu luar biasa, pada saat ini banyak sensor telah difabrikasi dengan ukuran sangat kecil sampai orde nanometer sehingga menjadikan sensor sangat mudah digunakan dan dihemat energinya.

\subsection{Ayam Broiler}

Ayam broiler merupakan ternak ayam yang pertumbuhan badannya sangat cepat dengan perolehan timbangan berat badan yang tinggi dalam waktu yang relatif pendek, yaitu pada umur 4-5minggu berat badannya dapat mencapai 1,2-1,9kg

Broiler secara umum memiliki ciri-ciri pertumbuhan cepat sebagai penghasil daging, konversi pakan irit, siap dipotong pada usia relatif muda, serta menghasilkan kualitas daging berserat lunak (Murtidjo, 2002). Siregaretal. (1980) menyatakan 
bahwa ayam broiler memiliki ciri khas yaitu pertumbuhan badannya cepat dan efisiensi tinggi untuk membentuk daging.Pada broiler dikenal dua fase pemeliharaan, yaitu:

1. Fase pemeliharaan awal (starter), yaitu anak broiler yang berumur 1 hari (DOC) sampai 3 atau 4 minggu.

2. Fase pemeliharaan akhir (finisher), yaitu pada masa ini broiler siap untuk dijual atau dipotong dengan umur lebih dari 4 minggu.

\section{Metode Penelitian}

\subsection{Rancangan Sistem}

Sistem ini menggunakan Arduino Mega 2560 yang berkomunikasi dengan Ethernet Shield. Input sistem berupa sensor DHT11 yang berfungsi sebagai komponen untuk memonitor suhu dan kelembaban kandang ayam broiler. Kontrol sistem Otomatis suhu dan kelembaban kandang ayam memanfaatkan panas cahaya lampu dan kipas, kemudian melalui komunikasi Ethernet Shield dengan Blynk, pemilik ternak bias memonitoring suhu dan kelembaban secara real time dengan android. Output sistem yaitu berupa kipas, Icd, lampu dan aplikasi android (Blynk).

\subsection{Rancangan Penelitian}

Metode perancangan yang dilakukan merupakan deskripsi yang disederhankan dari proses tahapan penelitian, yaitu proses perancangan alat yang sekuensial dimulai dari tahap analisis sistem sampai pengujian/evaluasi yang diperlihatkan pada gambar :

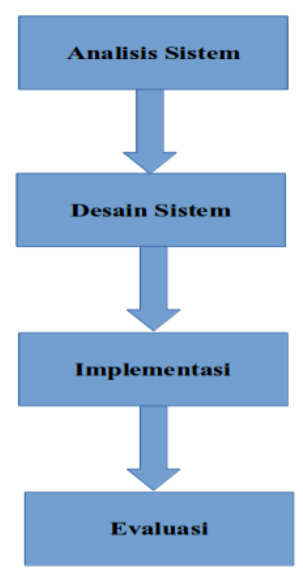

Gambar 3.1 Rancangan Penelitian 


\section{Journal Of Computer and Information System (J-CIS)}

ISSN 2622-0881 (online)

Penjelasan mengenai setiap tahapan pada gambar diatas adalah sebagai berikut :

a) Analisis Sistem

Pada tahapan ini berlangsung dengan melakukan studi awal mengenai masalah yang ada agar dapat diantisipasi segala permasalahan yang terkait dengan diterapkannya siste yang baru. Adapun masalah yang teridentifikasi :

1) Bagaimana memantau kondisi ruangan, suhu dan kelembaban dalam ruangan

2) Bagaimana merancang sistem monitoring menggunakan blynk yang dapat memonitoring secara realtime kondisi suhu dan kelembaban dalam kandang ayam

3) Bagaimana sensor-sensor tersebut dapat memudahkan pemilik kandang ayam dalam mengambil keputusan pengelolaan kandang ayam broiler

b) Desain

Desain yang digunakan untuk merancang sistem secara keseluruhan secara umum digambarkan sebagai berikut

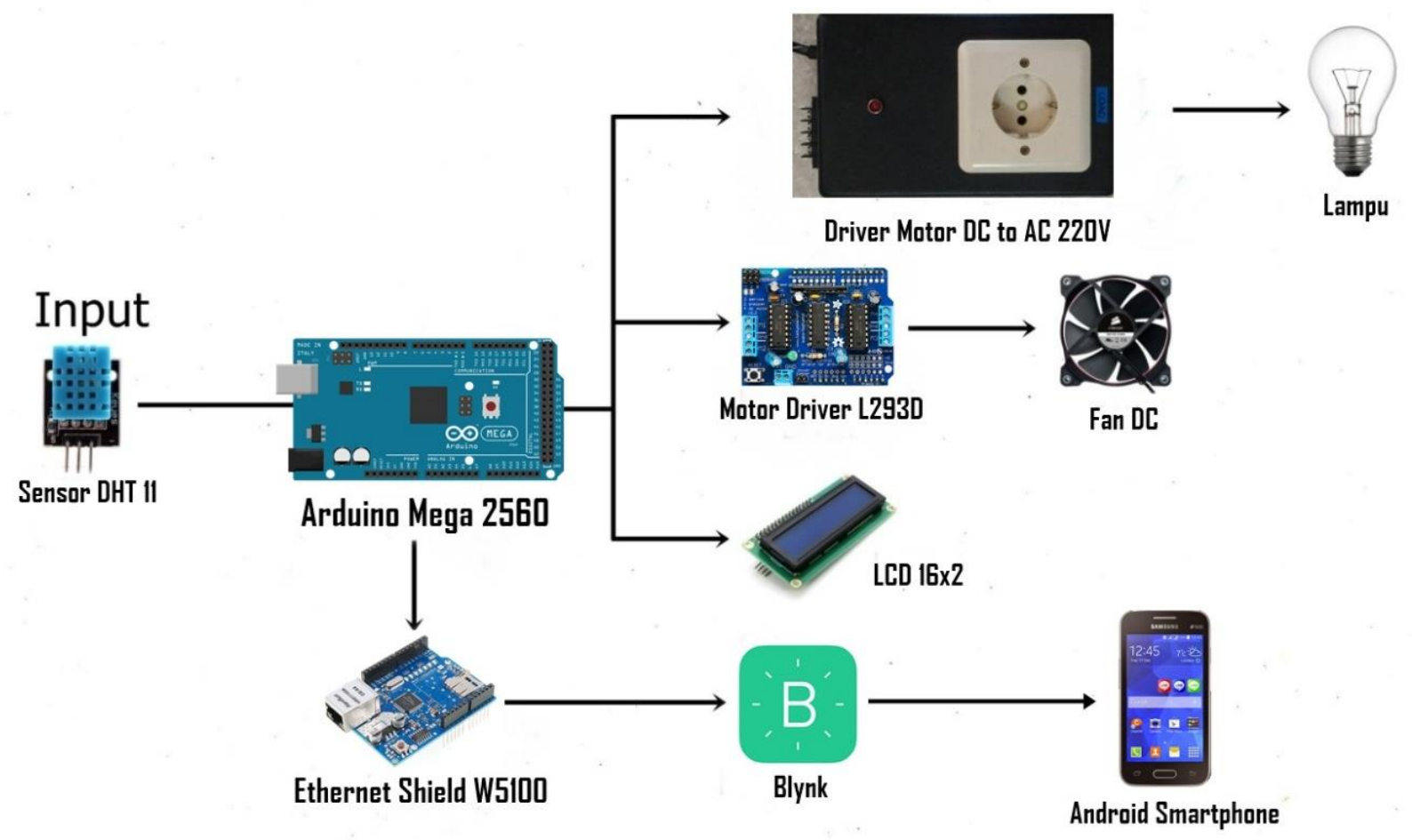

Gambar 3.2 Rancangan Alat 
Flowchart secara umum digambarkan sebagai berikut:

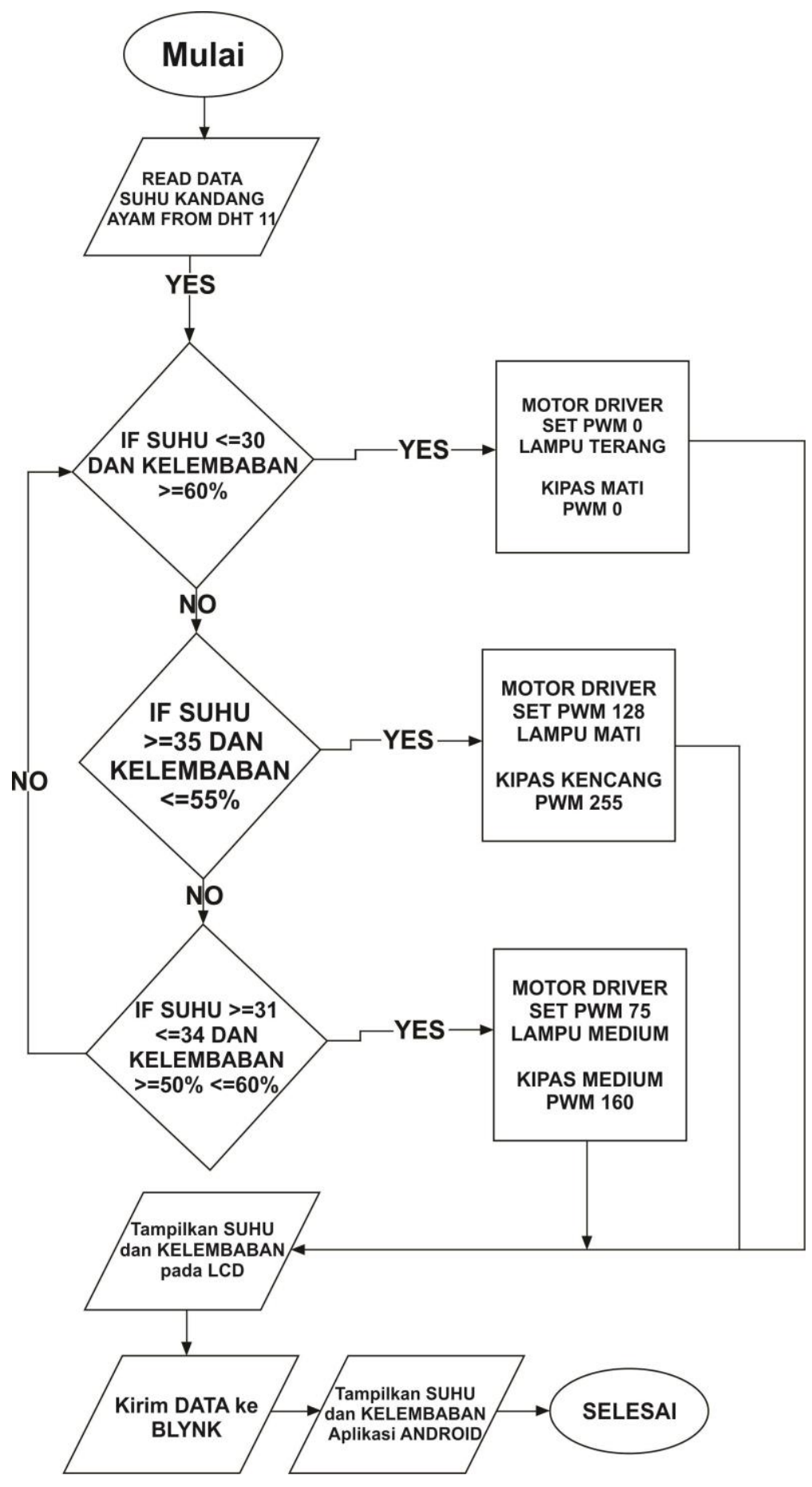

Gambar 3.3 flowchart sistem 


\subsection{Metode Pengujian}

Pada tahapan pengujian sistem ini, yaitu pengujian fungsional untuk menguji kinerja system dan alat secara keseluruhan, pengujian ini berfokus pada fungsi-fungsi setiap perangkat yang telah dirancang dalam sistem yang dibangun

\section{Hasil dan Pembahasan}

\subsection{Hasil}

Dari hasil penelitian yang dilakukan maka berhasil dirancang sebuah Sistem Kontrol kandang Otomatis pengatur suhu dan kelembaban kandang ayam broiler menggunakan arduino, Berikut gambar hasil perancangan alat.

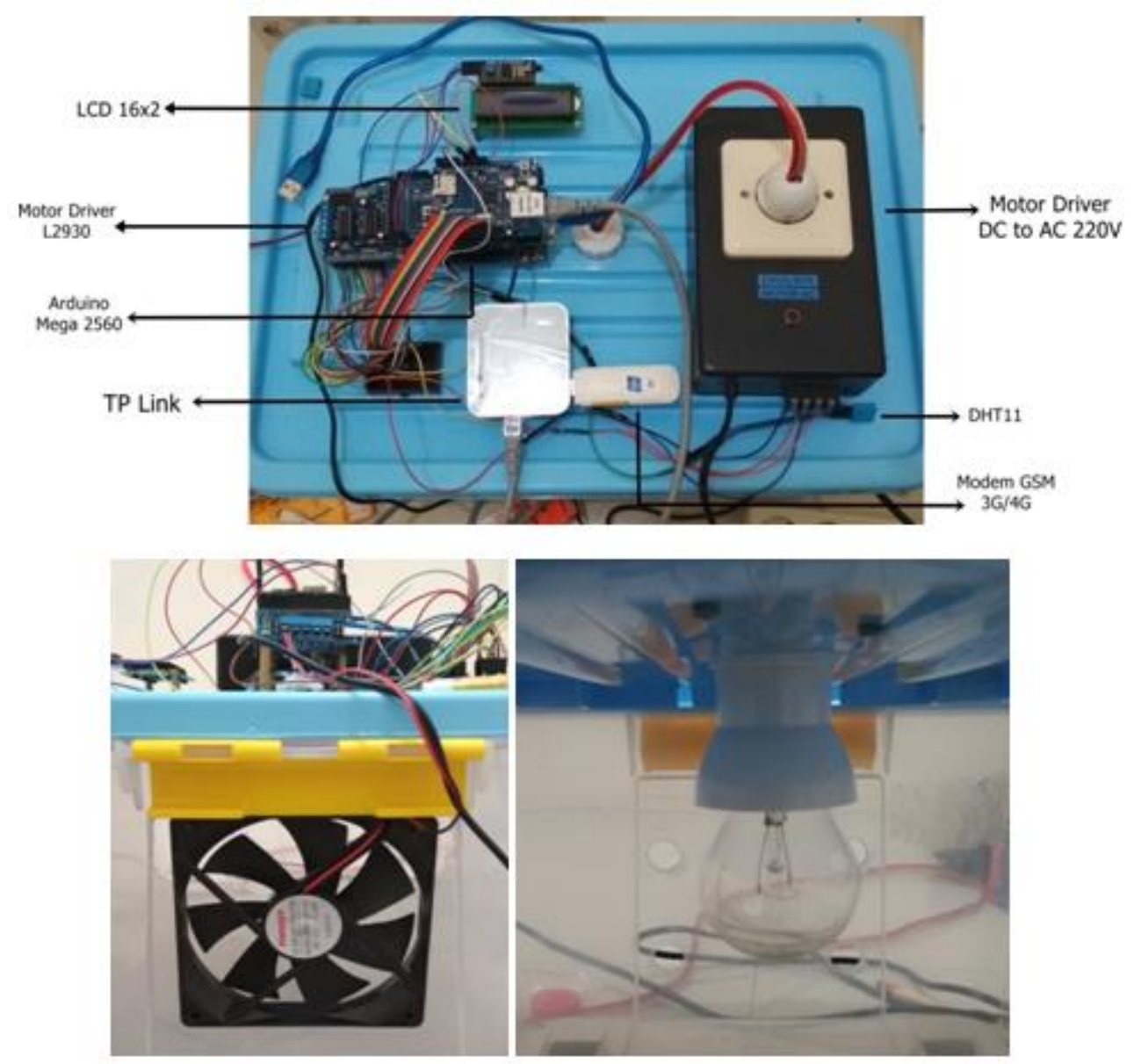

Gambar 4.1 Hasil Perancangan Alat 


\subsection{Pengujian Sensor DHT 11}

Pengujian ini dilakukan bertujuan untuk melihat sejauh mana kemampuan sensor dapat berhasil dalam melakukan monitoring Suhu dan Kelembaban pada kandang Ayam. DHT11 adalah sensor Suhu dan Kelembaban, memiliki keluaran sinyal digital yang dikalibrasi dengan sensor suhu dan kelembaban yang kompleks.Setiap sensor DHT11 memiliki fitur kalibrasi sangat akurat, dari kelembaban ruang kalibrasi. Kalibrasi dilakukan dengan mencocokkan suhu yang diukur oleh sensor suhu dan kelembaban DHT11 dengan Thermo Hygro digital. Pengujian dilakukan selama 190 Detik, dapat dilihat pada tabel dibawah:

Tabel 4.2 Pengujian Sensor DHT 11 dan Themo Hygrol

\begin{tabular}{|l|c|c|c|c|c|c|c|}
\hline No & Detik & $\begin{array}{c}\text { Sensor } \\
\text { DHT11 }\end{array}$ & $\begin{array}{c}\text { Thermo } \\
\text { Hygro }\end{array}$ & $\begin{array}{c}\text { Selisih } \\
\left({ }^{\circ} \mathrm{C}\right)\end{array}$ & $\begin{array}{c}\text { Selisih } \\
(\%)\end{array}$ & $\begin{array}{c}\text { Akurasi } \\
\left({ }^{\circ} \mathrm{C}\right)\end{array}$ & $\begin{array}{c}\text { Akurasi } \\
(\%)\end{array}$ \\
\hline 1 & 0 & $27^{\circ}-64 \%$ & $30^{\circ}-63 \%$ & $3^{\circ} \mathrm{C}$ & $1 \%$ & $97 \%$ & $99 \%$ \\
\hline 2 & 10 & $27^{\circ}-64 \%$ & $30^{\circ}-62 \%$ & $3^{\circ} \mathrm{C}$ & $2 \%$ & $97 \%$ & $98 \%$ \\
\hline 3 & 20 & $28^{\circ}-61 \%$ & $29^{\circ}-60 \%$ & $1^{\circ} \mathrm{C}$ & $1 \%$ & $99 \%$ & $99 \%$ \\
\hline 4 & 30 & $29^{\circ}-60 \%$ & $29^{\circ}-59 \%$ & $0^{\circ} \mathrm{C}$ & $1 \%$ & $100 \%$ & $99 \%$ \\
\hline 5 & 40 & $30^{\circ}-60 \%$ & $30^{\circ}-58 \%$ & $0^{\circ} \mathrm{C}$ & $2 \%$ & $100 \%$ & $98 \%$ \\
\hline 6 & 50 & $30^{\circ}-59 \%$ & $31^{\circ}-57 \%$ & $1^{\circ} \mathrm{C}$ & $2 \%$ & $99 \%$ & $98 \%$ \\
\hline 7 & 60 & $30^{\circ}-59 \%$ & $31^{\circ}-57 \%$ & $1^{\circ} \mathrm{C}$ & $2 \%$ & $99 \%$ & $98 \%$ \\
\hline 8 & 70 & $31^{\circ}-57 \%$ & $32^{\circ}-56 \%$ & $1^{\circ} \mathrm{C}$ & $1 \%$ & $99 \%$ & $99 \%$ \\
\hline 9 & 80 & $31^{\circ}-57 \%$ & $32^{\circ}-55 \%$ & $1^{\circ} \mathrm{C}$ & $2 \%$ & $99 \%$ & $98 \%$ \\
\hline 10 & 90 & $32^{\circ}-56 \%$ & $33^{\circ}-54 \%$ & $1^{\circ} \mathrm{C}$ & $2 \%$ & $99 \%$ & $98 \%$ \\
\hline 11 & 100 & $33^{\circ}-54 \%$ & $34^{\circ}-53 \%$ & $1^{\circ} \mathrm{C}$ & $1 \%$ & $99 \%$ & $99 \%$ \\
\hline 12 & 110 & $34^{\circ}-53 \%$ & $35^{\circ}-52 \%$ & $1^{\circ} \mathrm{C}$ & $1 \%$ & $99 \%$ & $99 \%$ \\
\hline 13 & 120 & $34^{\circ}-51 \%$ & $36^{\circ}-52 \%$ & $2^{\circ} \mathrm{C}$ & $1 \%$ & $98 \%$ & $99 \%$ \\
\hline 14 & 130 & $35^{\circ}-49 \%$ & $37^{\circ}-50 \%$ & $2^{\circ} \mathrm{C}$ & $1 \%$ & $98 \%$ & $99 \%$ \\
\hline 15 & 140 & $36^{\circ}-49 \%$ & $37^{\circ}-50 \%$ & $1^{\circ} \mathrm{C}$ & $1 \%$ & $99 \%$ & $99 \%$ \\
\hline 16 & 150 & $37^{\circ}-48 \%$ & $38^{\circ}-49 \%$ & $1^{\circ} \mathrm{C}$ & $1 \%$ & $99 \%$ & $99 \%$ \\
\hline 17 & 160 & $37^{\circ}-46 \%$ & $39^{\circ}-48 \%$ & $2^{\circ} \mathrm{C}$ & $2 \%$ & $98 \%$ & $98 \%$ \\
\hline 18 & 170 & $38^{\circ}-46 \%$ & $40^{\circ}-48 \%$ & $2^{\circ} \mathrm{C}$ & $2 \%$ & $98 \%$ & $98 \%$ \\
\hline 19 & 180 & $38^{\circ}-45 \%$ & $41^{\circ}-47 \%$ & $3^{\circ} \mathrm{C}$ & $2 \%$ & $97 \%$ & $98 \%$ \\
\hline 20 & 190 & $39^{\circ}-44 \%$ & $42^{\circ}-46 \%$ & $3^{\circ} \mathrm{C}$ & $3 \%$ & $97 \%$ & $97 \%$ \\
\hline & RATA-RATA AKURASI SUHUDAN KELEMBABAN & $98,50 \%$ & $98,45 \%$ \\
\hline
\end{tabular}

Berdasarkan tabel diatas tingkat keakurasian pengujian data selama 190 detik pada sensor DHT11, maka rata-rata akurasi suhu dan kelembabannya masing-masing adalah $98 \%$ seperti terlihat pada perhitungan berikut ini: 


$$
\begin{aligned}
\text { Suhu: } \frac{97+97+99+100+100+99+99+99+99+99+99+99+98+98+97+97}{20} \\
=\frac{1970}{20} \\
=98,50
\end{aligned}
$$

Kelembapan

$$
\begin{aligned}
=\frac{99+98+99+99+98+98+98+99+98+98+99+99+99+99+99+99+98+98+98+97}{20} \\
=\frac{1969}{20} \\
=98,45
\end{aligned}
$$

\section{Kesimpulan}

Dari pembahasan dan analisis pada bab-bab sebelumnya, dapat disimpulkan bahwa:

1. Perancangan pengaturan suhu kandang ayam secara otomatis berjalan dengan baik karena alat dapat bekerja dan menjaga kestabilan suhu sesuai dengan tiga batasan suhu yang telah ditentukan, yaitu Dingin ( $\mathrm{Suhu}<=30^{\circ}$ dan Kelembaban $>=60 \%$ ), panas (Suhu $>=35^{\circ}$ dan Kelembaban $<=55 \%$ ), dan normal (Suhu $>=31^{\circ}$ dan Kelembaban $>=50 \%$ dan $<=60 \%$ ).

2. Penggunaan Arduino Uno (32 KB) dialihkan ke Arduino MEGA 2560 (256 KB) sebab Sistem sangat menguras memory flash Arduino, membuat kalibrasi alat menjadi lambat.

\section{DAFTAR PUSTAKA}

Abdul Kadir. 2012. Panduan Praktis Mempelajari Aplikasi Mikrokontroler dan Pemrogramannya menggunakan arduino. Yogyakarta: Andi Yogyakarta

Arduino: Belajar cepat dan Pemrograman. Jakarta: Informatika

Gunawan, Sihombing , 2004, meneliti tentang pengaruh suhu lingkungan tinggi terhadap kondisi fisiologis dan produktivitas ayam buras.

Komang Ardana, Ida Bagus. 2009. Ternak Broiler. Denpasar: Penerbit Gava Swasta Nulus.

Miftahul Arifien. 2014. Ayam Broiler di Daerah Tropis. Bandung: Penebar Swadaya

Rio, Osea Zebua, 2013, meneliti tentang Perancangan Sistem Pengaturan Suhu Kandang Ayam Berbasis Mikrokontroler 
Setiawan, Iwan. 2006. Programmable Logic Controller dan Perancangan Sistem Kontrol. Yogyakarta: Penerbit Gramedia.

Siregar, A.P., dan M. Sabrani. 1970. Teknik Modern Beternak Ayam. C.V

Sonty, Aditya, 2014 meneliti tentang Perancangan Dan Implementasi Pemantau Suhu Serta Penanganan Dini Kandang Ayam Boiler Berbasis Mikrokontroler

Suprijatna, E. Umiyati, A. Ruhyat, K. 2005.IImu Dasar Ternak Unggas. Penebar

Sutanto,H.2012.SAKLAR DIMMER LAMPU EMPAT TAHAP FILKOM/DC/PI/00001/2012

Thiang, Resmana,Wahyudi, 2001, meneliti tentang Pemanfaatan Pulse Width Modulation untuk mengontrol Motor (Studi kasus Robot Otomatis dua deviana)

Widodo Budiharto. 2011. Aneka Proyek Mikrokontroler. Jakarta: Graha IImu 